\title{
DIAGNÓSTICO FOTODINÂMICO: PRINCÍPIOS E APLICAÇÕES
}

\author{
Taise Maria dos Anjos Oliveira ${ }^{1}$; Amanda Vargas Teles ${ }^{1}$; Fábio de Castro Bezerra ${ }^{2}$; \\ Pablo José Gonçalves ${ }^{3}$; Guilherme Rocha Lino de Souza ${ }^{4}$ \\ ${ }^{1}$ Mestrandas do Programa de Pós-graduação em Ciência Animal da Escola de \\ Veterinária e Zootecnia da Universidade Federal de Goiás -UFG \\ Email: taise.vet@hotmail.com \\ ${ }^{2}$ Doutorando do Programa de Pós-graduação em Física do Instituto de Física da \\ Universidade Federal de Goiás -UFG \\ ${ }^{3}$ Docente do Programa de Pós-graduação do Instituto de Física da Universidade \\ Federal de Goiás -UFG \\ ${ }^{4}$ Docente do Programa de Pós-graduação da Escola de Veterinária e Zootecnia da \\ Universidade Federal de Goiás -UFG
}
Recebido em: 08/09/2015 - Aprovado em: 14/11/2015 - Publicado em: 01/12/2015 DOI: http://dx.doi.org/10.18677/Enciclopedia_Biosfera_2015_136

Nos últimos anos, houve um crescimento na utilização de técnicas baseadas em fluorescência. Entretanto, na Medicina Veterinária tais técnicas são pouco difundidas e utilizadas. Diante da necessidade de um maior esclarecimento na utilização dessas técnicas para auxiliar o diagnóstico de enfermidades, o objetivo principal deste trabalho foi englobar as principais aplicações do fotodiagnóstico, bem como os fotossensibilizadores mais utilizados neste processo. O diagnóstico fotodinâmico baseia-se na forma em que tecidos normais e anormais absorvem a luz, permitindo então a visualização de fluorescência diferencial nestes tecidos quando em contato com fluoróforos. Estes fluoróforos podem ser endógenos ou exógenos, e emitem fluorescência ao serem excitados por um comprimento de onda específico da luz visível dentro da gama do espectro. Os fluoróforos exógenos são chamados de fotossensibilizadores e possuem um papel fundamental no fotodiagnóstico, pois são moléculas capazes de interagir com luz e gerar fluorescência ou espécies reativas do oxigênio. Esta técnica pode ser aplicada para o diagnóstico de diversas enfermidades, como, por exemplo, no diagnóstico de fungos de pele, na detecção da cárie dentária, cálculos e biofilmes bacterianos, na detecção de pequenas lesões no trato digestório e principalmente no diagnóstico precoce do câncer e no tratamento de neoplasias. Por ser uma técnica inovadora, que apresenta uma alta sensibilidade e especificidade, não ser invasiva, além de ser uma técnica rápida e de fácil realização, o diagnóstico fotodinâmico apresenta um enorme potencial de utilização na Medicina Veterinária.

PALAVRAS-CHAVE: fotodiagnóstico, fotossensibilizadores, fluorescência, porfirina. 


\title{
PHOTODYNAMIC DIAGNOSIS: PRINCIPLES AND APPLICATIONS
}

\begin{abstract}
In recent years, the use of fluorescence-based techniques has greatly increased. However, the use of such techniques in Veterinary Medicine is not widespread. Considering the need for further information on the use of these techniques to assist the diagnosis of diseases, the objective of this review was to cover the main applications of photodiagnosis as well as the photosensitizers more used in this process. Photodynamic diagnosis is based on the manner in which normal and abnormal tissues absorb light, allowing fluorescence on these tissues when they are in contact with a fluorophore. These fluorophores may be endogenous or exogenous, and emit fluorescence when excited by light of a specific wavelength. The fluorophores are called exogenous photosensitizers and have a key role in photodiagnosis. They are molecules capable of interacting with light-generating fluorescence or reactive oxygen species. This technique can be applied to the diagnosis of many diseases, such as skin fungi, detection of dental caries, bacterial biofilms, detection of small lesions in the digestive tract, and especially in the early diagnosis of cancer and treatment of neoplasms. Being an innovative non-invasive technique, with high sensitivity and specificity, as well as relatively quick and easy to perform, photodynamic diagnosis presents potential for use in veterinary medicine.
\end{abstract}

KEYWORDS: photodiagnosis, photosensitizers, fluorescence, porphyrin.

\section{INTRODUÇÃO}

O correto diagnóstico de uma enfermidade exige o conhecimento e investigação do Médico Veterinário, a fim de defini-lo em menor tempo e iniciar o tratamento mais adequado para cada situação. O método mais antigo de diagnóstico é a inspeção visual, esta vem sendo utilizada como parte do exame clínico desde o tempo de Hipócrates, porém, em vários casos a inspeção visual sozinha não permite confirmar a hipótese diagnóstica, sendo necessário o auxilio de outros métodos diagnósticos como, por exemplo, exames laboratoriais (MOGHISSI et al., 2008).

A utilização biomédica de técnicas baseadas em fluorescência vem crescendo a cada dia, tanto no campo do diagnóstico, como no campo do tratamento clínico (ANDERSSON-ENGELS et al., 1997). O diagnóstico fotodinâmico surgiu como uma importante ferramenta diagnóstica, por ser uma técnica rápida, de fácil realização, não invasiva, seletiva e sensível (SIERON et al., 2013). Muitas aplicações desse método têm sido discutidas em diferentes áreas médicas, como a dermatologia, gastroenterologia, odontologia, pneumologia, ortopedia, urologia, neurologia e principalmente na oncologia (SIERON \& KWIATEK, 2009; WOLUN-CHOLEWA et al., 2011; AHMAD et al., 2012; CHEUNG et al., 2013; BORRONI et al., 2015; YAMAMOTO et al., 2015).

O método baseia-se no princípio da emissão de fluorescência, em resposta a uma excitação por um comprimento de onda específico da luz visível dentro da gama do espectro (MOGHISSI et al., 2008; GUYON et al., 2012). No diagnóstico de câncer haverá emissão de fluorescência diferencial entre o tecido anormal e os tecidos normais, sendo o resultado muito sensível e específico (MOGHISSI et al., 2008). Na prática clínica são utilizados dois tipos de métodos de diagnóstico fotodinâmico, a autofluorescência e a fluorescência induzida por fluoróforos exógenos (MOGHISSI et al., 2008; SIERON et al., 2013). A autofluorescência é gerada pelas moléculas endógenas, tais como os ácidos aminados aromáticos, 
nicotinamida adenina dinucleotídeo (NADH) ou porfirinas. Já a fluorescência exógena é baseada na utilização de fotossensibilizadores, que possuem seletividade pelo tecido pesquisado, tais como porfirinas, ftalocianinas e clorinas (DACOSTA et al., 2007; FILIP et al., 2011).

Fotossensibilizadores (PS) são moléculas capazes de interagir com a luz e gerar fluorescência, ou ainda, gerar espécies reativas do oxigênio (ALLISON et al., 2008). Seus espectros de excitação e emissão são bem conhecidos, e sua aplicabilidade está relacionada principalmente à localização seletiva dentro dos tecidos de interesse, modo de administração, visualização da fluorescência a olho nu ou por meio do fluorímetro e poucos efeitos colaterais para os pacientes (BORISOVA et al., 2011).

O diagnóstico fotodinâmico já é utilizado na Medicina há alguns anos, principalmente no diagnóstico precoce de câncer, porém, pouco utilizados na Medicina Veterinária. Desta forma, esta revisão teve como intuito abordar os processos fotofísicos que ocorrem com os fluoróforos, os fotossensibilizadores utilizados e os métodos de diagnóstico fotodinâmico que podem ser aplicados na Medicina Veterinária.

\section{PROCESSOS FOTOFÍSICOS}

Quando uma molécula é excitada, ela se encontrará num estado energeticamente instável em relação ao seu estado fundamental. Caso essa molécula não sofra rearranjo ou se fragmente (processo químico), perderá energia para retornar ao estado fundamental (processo físico) (BRACKMANN, 2000). As moléculas podem perder energia por processos radioativos, não radioativos e de supressão. Os processos radioativos são classificados como fenômenos de luminescência (fosforescência e fluorescência), através dos quais os estados excitados decaem ao estado fundamental, com a emissão de radiação eletromagnética (EWING, 1975; BRACKMANN, 2000).

A luminescência é o resultado de um processo de três fases que ocorre com os fluoróforos ou corantes fluorescentes, que culminará na fluorescência, fosforescência ou na transferência de energia não radioativa. $O$ processo responsável pela luminescência é ilustrado pelo diagrama de Jablonski (Figura 1). Após a absorção de radiação por um comprimento de onda específico, as moléculas são promovidas do estado fundamental $\left(S_{0}\right)$ para um estado excitado singleto $\left(S_{n}\right)$, essas moléculas se desativam por relaxamento vibracional (RV) até atingir o primeiro nível vibracional do estado excitado singleto de menor energia $\left(\mathrm{S}_{1}\right)$. Esse processo de relaxamento recebe o nome de cruzamento interno $(\mathrm{Cl})$ que consiste na desativação da espécie excitada para estados de mesma multiplicidade de spin e sem emissão de radiação. A partir de $S_{1}$, o elétron pode seguir três caminhos: 1) conversão interna e conversão externa (processo não radiativo onde há perda de energia da molécula para o solvente); 2) emitir luz visível através do processo de fluorescência ou ainda 3 ) passar para um estado de menor energia tripleto $\left(T_{1}\right)$ por efeito de cruzamento intersistemas (CIS) onde há a passagem de singleto para tripleto com inversão do spin (EWING, 1975; LAKOWICZ, 2007; LEHNINGER et al., 2008). 


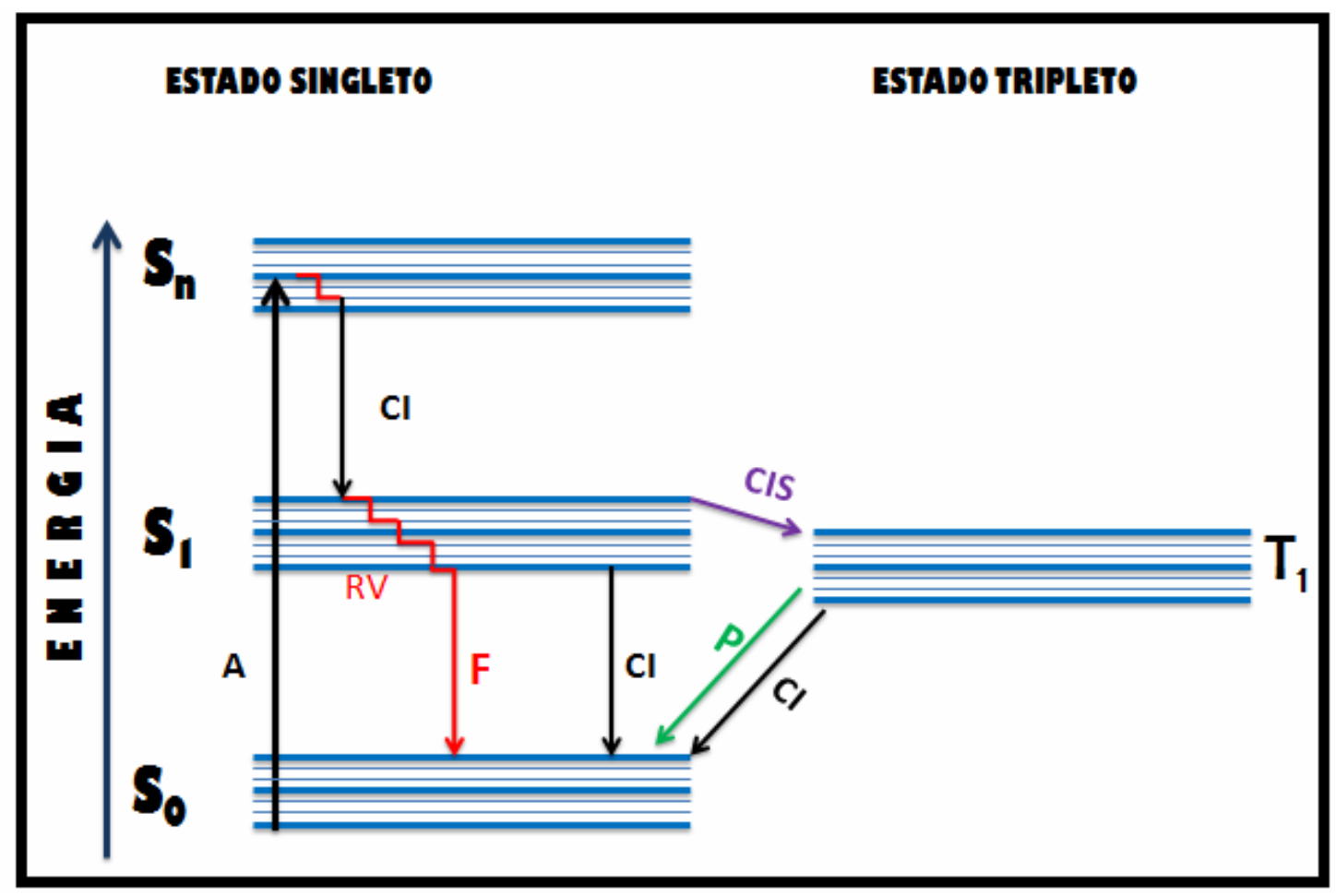

FIGURA 1. Diagrama de Jablonski modificado. $\left(S_{0}\right)$ estado fundamental, $\left(S_{n}\right)$ estado excitado singleto, $\left(S_{1}\right)$ primeiro estado excitado singleto, (A) absorção de um fóton, (RV) relaxamento vibracional, (Cl) cruzamento interno, (CIS) cruzamento intersistemas, (T1) estado excitado tripleto de menor energia, (F) Fluorescência, (P) Fosforescência.

Fonte: Adaptado de FRACKOWIAK (1988)

Se o estado excitado envolvido é singleto, onde o spin do elétron no orbital excitado mantém a orientação original $\left(S_{1}-S_{0}\right)$, tem-se a fluorescência. Porém, no estado tripleto $\left(T_{1}\right)$, o elétron pode emitir luz e voltar para o estado fundamental $\left(\mathrm{S}_{0}\right)$ ocorrendo outro cruzamento entre sistemas $\left(T_{1}-S_{0}\right)$ acompanhado de emissão de luz visível, ou seja, o fenômeno de fosforescência, ou pode ainda transfererir energia para outra molécula por meio de uma transição não radioativa, dando origem a espécies reativas de oxigênio (ROS). Na fluorescência não ocorre cruzamento entre sistemas, e não há inversão de spin. A necessidade de inversão de spin para o fenômeno de fosforescência o torna mais lento que a fluorescência, sendo assim, a fluorescência é um fenômeno luminescente mais comum que a fosforescência (EWING, 1975; LAKOWICZ, 2007; LEHNINGER et al., 2008).

Alguns fatores podem influenciar no fenômeno da fluorescência, como: conformação apropriada da molécula, o meio que deve favorecer a desativação radioativa $\left(\mathrm{S}_{1}-\mathrm{S}_{0}\right.$ ), temperatura e $\mathrm{pH}$ (SCHULMAN \& SANDERS, 1971). A conformação molecular planar aumenta a interação e conjugação entre os elétrons favorecendo a fluorescência, assim como a presença de grupos substituintes como os grupos hidroxi (-OH), metoxi (-OR), amino (-NR2), que amplificam a intensidade e o tipo de luminescência, enquanto os grupos cetônicos $(-\mathrm{C}=\mathrm{O})$ carboxílicos $(-\mathrm{COOH})$ e halogênios $(-X)$ favorecem o cruzamento intersistemas, levando a fosforescência. O aumento da temperatura leva a uma maior eficiência dos processos de 
relaxamento vibracional $(\mathrm{Cl})$ com consequente desativação do estado excitado, já o $\mathrm{pH}$ possui efeito relevante em moléculas aromáticas, contendo grupos funcionais básicos ou ácidos, sendo comum observar diferença entre as propriedades luminescentes de moléculas protonadas e não-protonadas (INGLE \& $\mathrm{CROUCH}$, 1988).

\section{FOTOSSENSIBILIZADORES}

Fotossensibilizadores (PS) são moléculas capazes de interagir com a luz e gerar fluorescência, ou ainda, gerar espécies reativas do oxigênio (ALLISON et al., 2008). Um PS ideal deve apresentar as seguintes características: baixa toxicidade na ausência de luz, ser um composto puro, hidrossolúvel, biologicamente estável, fotoquimicamente seletivo, apresentar intensa absorção na região espectral entre 600 a $700 \mathrm{~nm}$, baixos custos de produção e rápida excreção do organismo (PUSHPAN et al., 2002).

Os fotossensibilizadores podem ser classificados como de primeira, segunda ou terceira geração (SENGE, 2012). A primeira geração de fotossensibilizadores era composta por substâncias derivadas da hematoporfirina $(\mathrm{HpD})$, com estrutura tetrapirrol, semelhante à da protoporfirina contida na hemoglobina (DEROSA \& CRUTCHLEY, 2002). A heterogeneidade química destes PS aliada aos baixos coeficientes de absorção e efeitos colaterais como a fotossensibilidade prolongada da pele (até 12 semanas) incentivaram o desenvolvimento de uma segunda geração de PS como o ácido 5-aminolevulínico (ALA) (O'CONNOR et al., 2009). Já a terceira geração de PS corresponde à conjugação entre os PS de segunda geração com anticorpos, polímeros, lipossomas, ou outras moléculas que permitam direcionar seletivamente o PS para o tecido de interesse (NYMAN \& HYNNINEN, 2004; O'CONNOR et al., 2009).

A distribuição do fotossensibilizador no organismo ocorre pela interação com os receptores de lipoproteína de baixa densidade (LDL). No caso de neoplasias, as células cancerosas apresentam elevados níveis de receptores de LDL, assim, ocorre a formação de complexos LDL-fotossensibilizador, permitindo o diagnóstico e a aplicação da terapia fotodinâmica (CHOWDHARY et al., 2003). Outro fator que permite a distribuição é a captação seletiva do PS pelas células tumorais que ocorre devido ao menor $\mathrm{pH}$ intracelular, microcirculação permeável e drenagem linfática deficiente nos tumores (FOOTE, 1968). A maioria dos fotossensibilizadores não se acumula no núcleo celular, eles se ligam a matrizes apolares endocelulares como lisossomos, mitocôndrias e/ ou membranas plasmáticas (KRAMER-MAREK et al., 2006).

Historicamente três famílias de corantes têm sido mais estudadas para utilização no fotodiagnóstico e na terapia fotodinâmica, são as porfirinas, clorinas e ftalocianinas, que serão abordadas a seguir.

\section{- Porfirinas}

A palavra porfirina tem origem do grego "porphura" e era utilizada para descrever a cor púrpura. Assim, porfirina é o nome dado à grande classe de compostos vermelhos ou púrpuros, pigmentos cristalinos fluorescentes, de origem natural ou sintética, que têm em comum um macrocíclo aromático consistindo de quatro anéis pirrólicos, ligados entre si por pontes de metil (SMITH, 1998).

As porfirinas são compostas por 20 átomos de carbono ao redor de um anel central com quatro átomos de nitrogênio, sendo assim, são capazes de absorver luz 
na região visível e transmitir esta energia para moléculas vizinhas (Figura 2). Possui elevado rendimento quântico de formação de tripleto e geração do oxigênio singleto, além de biocompatibilidade com diversas estruturas biológicas, como albuminas, micelas e DNA (SMITH, 1998; LEHNINGER et al., 2008).

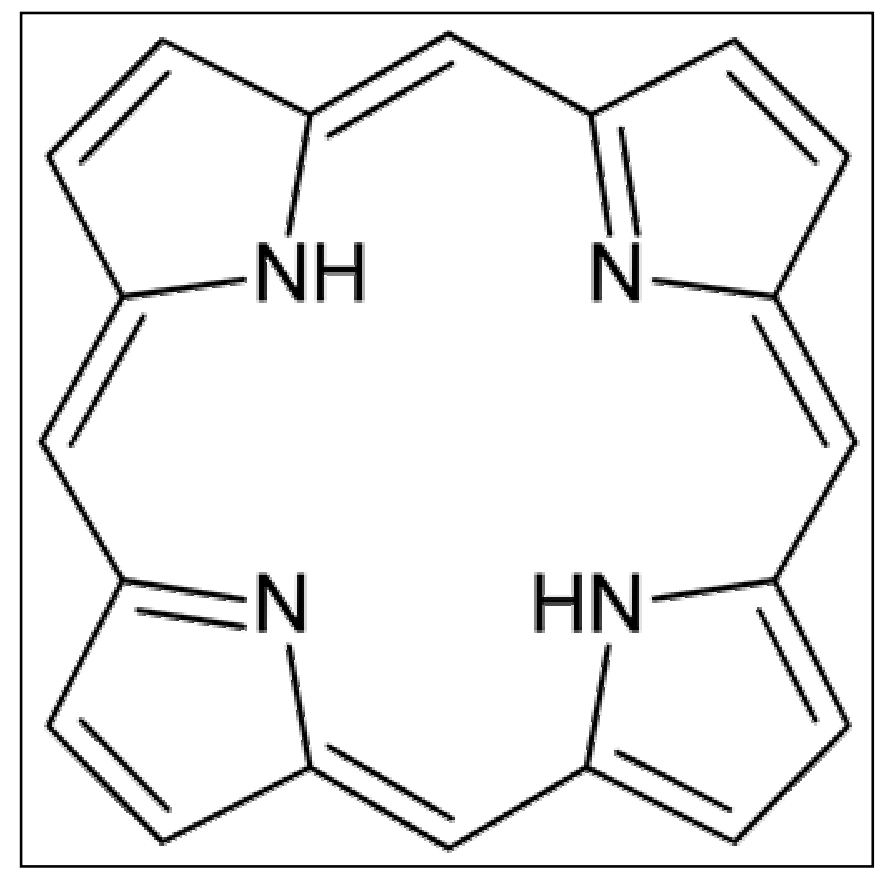

FIGURA 2. Fórmula estrutural da porfirina.

São classificadas ainda em primeira, segunda ou terceira geração. As de primeira geração são aquelas porfirinas que são substituídas nas posições meso do anel, por grupos fenila ou arila. As porfirinas de segunda geração possuem uma maior ativação do anel frente a reações de oxidação, pois possuem halogênios nos grupos fenílicos das posições meso. E por fim, as porfirinas de terceira geração são aquelas que apresentam halogênios ou outros tipos de substituintes volumosos nas posições $\beta$-pirrólicas do anel (posições 2, 3, 7, 8, 12, 13, 17 e 18), conferindo a estas porfirinas maior proteção à destruição oxidativa e minimizando a formação de espécies diméricas (MONTANARI, 1994; DOLPHIN et al., 1997).

As porfirinas são fundamentais em alguns processos biológicos, como: transporte de oxigênio (hemoglobina), armazenamento de oxigênio (mioglobina), transporte de elétrons na cadeia respiratória (citocromo c) e na fotossíntese (clorofila). Na Medicina, as porfirinas trouxeram uma inovação no campo do diagnóstico e na terapia fotodinâmica para o câncer e pode ser aplicada no combate de diversas doenças (SESSLER \& WEGHORN, 1997).

Como dito anteriormente, os primeiros fotossensibilizadores utilizados foram derivados desta família, os principais análogos comercias são os Photofrin $\AA$, Photosan®, Photogem® e Metvix®. Esses PS são produzidos a partir da tecnologia de desfibrilação do sangue de animais e de humanos, a partir de protoporfirina IX (HpIX) existente na circulação sanguínea (MIRONOV et al., 1990). Estes apresentam espectro de absorção em cinco bandas, sendo a mais intensa na região de $370 \mathrm{~nm}$, conhecida como banda de Soret, e quatro bandas de menor intensidade em comprimentos de onda maiores (bandas $Q$ ) em torno de $630 \mathrm{~nm}$ ( DOUGHERTY et al., 1975; BRAGA et al., 2014) (Figura 3). 


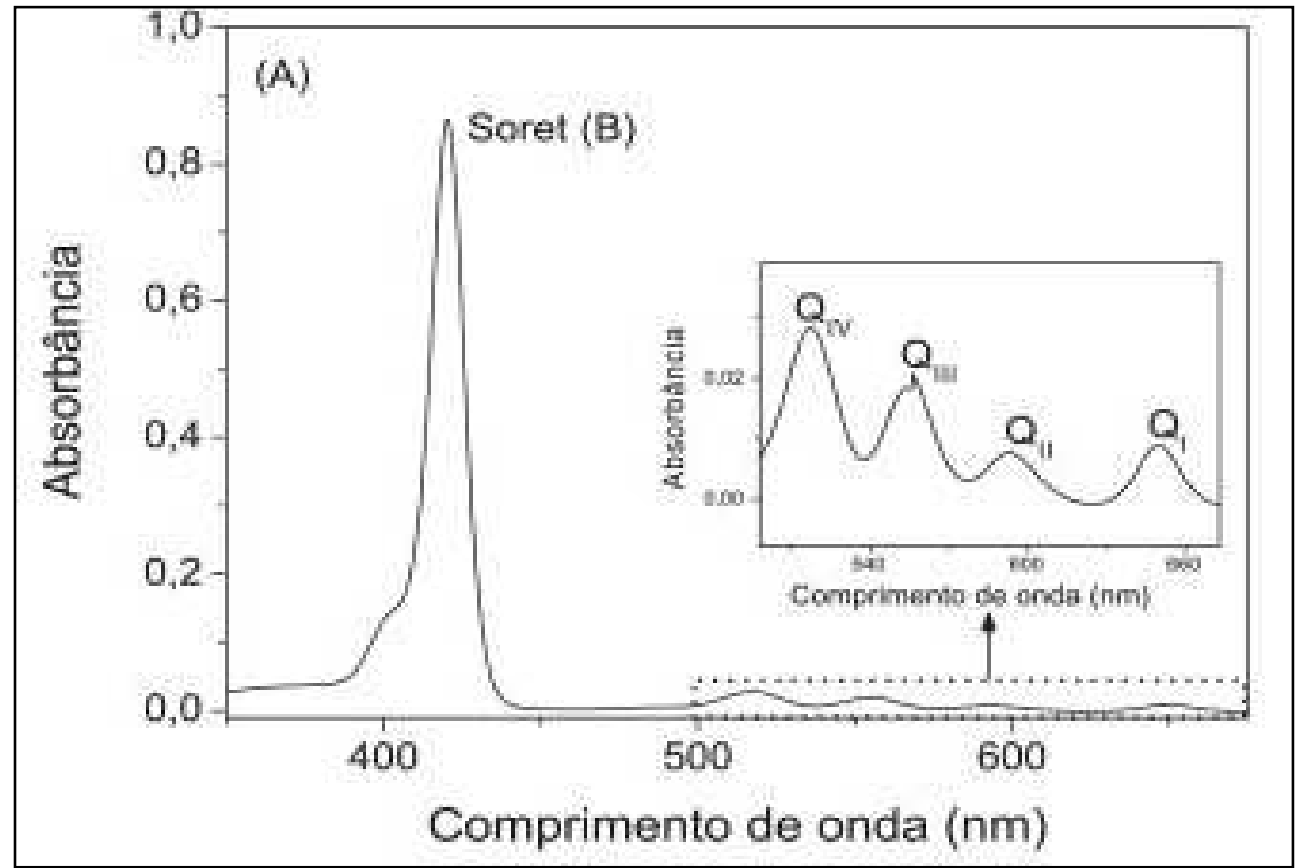

FIGURA 3. Espectro de absorção eletrônica da porfirina. Na região de $370 \mathrm{~nm}$ o espectro da banda de Soret que possui maior intensidade e quatros bandas $Q$ de menor intensidade em torno de $630 \mathrm{~nm}$.

Fonte: Adaptado de BRAGA et al.(2014)

Os PS derivados de porfirinas não são considerados ideais por apresentarem elevada retenção cutânea, causando um efeito colateral indesejável que consiste na fotossensibilização cutânea do paciente que deve se proteger da exposição à luz solar ou luz brilhante por um período de quatro a oito semanas, que é o tempo de retenção do $\mathrm{HpD}$ na pele. Além disso, a última banda de absorção destes PS encontra-se na faixa de 620-630 nm e neste comprimento de onda a penetração de luz nos tecidos não é ideal (BRAGA et al., 2014).

- Clorinas

As clorinas são porfirinas hidrofílicas reduzidas devido à saturação de uma dupla ligação na periferia do sistema macrocíclico (BOSE \& DUBE, 2008). Apresentam forte banda de absorção na região de 650-800nm e apesar de serem semelhantes às porfirinas, as clorinas apresentam um deslocamento para a região do vermelho no espectro de UV-visível da última banda $Q$, assim como, um aumento no coeficiente de extinção molar desta banda. Essa característica permite que as clorinas absorvam fortemente na região do azul e do vermelho, e possuam maior tempo de vida de estado tripleto. Estas características fazem com que as clorinas se destaquem no mercado, e possuam uma variedade de análogos comerciais como: Foscan $\AA^{\circledR}$, Photochlor ${ }^{\circledR}$, Photoditazine ${ }^{\circledR}$, Radaclorina ${ }^{\circledR}$ e Visudyne ${ }^{\text {TM }}$ (STRACHAN et al., 2000; BOSE \& DUBE, 2008). 


\section{- Ftalocianinas}

As Ftalocianinas são corantes sintéticos semelhantes às porfirinas e estruturalmente consideradas azaporfirinas (SPIKES, 1986). O termo ftalocianina possui origem nas palavras gregas "nafta", que significa rocha e "cyanine", que significa azul escuro. Este termo foi utilizado pela primeira vez para descrever essa classe de compostos macrocíclicos por Reginald Linstead em 1933 durante seu trabalho pioneiro sobre o assunto (VALEUR, 2001).

São constituídas de quatro núcleos benzoindólicos unidos por pontes de nitrogênio (Figura 4), e são classificadas como fotossensibilizadores de segunda geração (SPIKES, 1986; ROSENTHAL, 1991). Podem estar ligadas a uma variedade de metais, principalmente alumínio e zinco, se acumulam na membrana plasmática, microssomos e mitocôndria, e apresentam uma intensa banda de absorção na região de 700nm (ROSENTHAL, 1991).

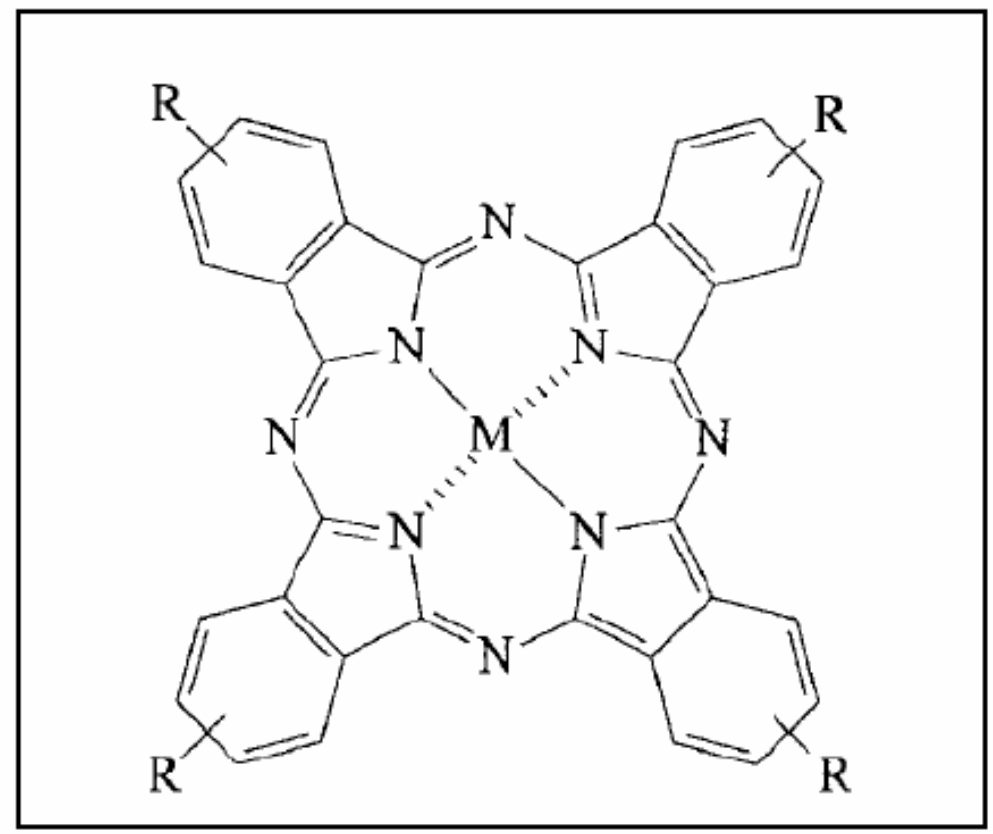

FIGURA 4. Fórmula estrutural da Ftalocianina. A letra $M$ representa o centro do átomo que é ocupado por um metal (Al, Co, $\mathrm{Ga}, \mathrm{Si}, \mathrm{Zn})$

Os principais fotossensibilizadores análogos da Ftalocianina são 0 Photosense $\AA$, o PC4, ZnPc e o CIAIPc que ainda não possuem análogos comerciais (BARON et al., 2010; XU et al., 2012; JIANG et al., 2014).

\section{DIAGNÓSTICO FOTODINÂMICO}

O fotodiagnóstico se baseia no princípio que tecidos anormais absorvem a luz de forma diferente dos tecidos normais, assim ao utilizar comprimentos de onda específicos aos fluoróforos, sejam endógenos ou exógenos, irão emitir fluorescência característica (GUYON et al., 2012; INOUE et al., 2014). 
O monitoramento da fluorescência pode ser baseado na autofluorescência do tecido por meio de fluoróforos endógenos, ou resultante da administração de fluoróforos exógenos que se acumulam seletivamente em lesões de interesse diagnóstico (MOGHISSI et al., 2008; SIERON et al., 2013; DRAKAKI et al., 2014). A fluorescência endógena é preferível, uma vez que não há efeitos colaterais indesejáveis ou riscos associados à utilização de PS exógenos (ANDERSSONENGELS et al., 1997).

A autofluorescência é gerada por moléculas endógenas, como: aminoácidos aromáticos, proteínas estruturais, enzimas e coenzimas, vitaminas, lipídios e porfirinas (BORISOVA et al., 2011; FILIP et al., 2011). O espectro de excitação se encontra entre 250 e $450 \mathrm{~nm}$ e o espectro de emissão encontra-se por volta de 700 nm (RICHARDS-KORTUM \& SEVICK-MURACA, 1996; ZHAO et al., 2015). Este método tem sido descrito como muito sensível e específico no diagnóstico de pequenas alterações, que não são visíveis utilizando-se a luz endoscópica comum (ROBERTS-THOMSON et al., 2010; ZHAO et al., 2015). A fluorescência de cor vermelha é mais forte no tecido tumoral do que no tecido normal, onde a principal cor de fluorescência é verde. A desvantagem é a geração de falsos positivos devido à inflamação local ou neovascularização, porém, no mercado já existem aparelhos de laser que possuem um sistema de excitação utilizando luz azul, filtros de passagem e intensificadores de imagem que permitem a detecção de ambas às cores de autofluorescência (verde e vermelho), permitindo o correto diagnóstico (BORISOVA et al., 2011; OSADA et al., 2011).

A fluorescência exógena baseia-se na utilização de fotossensibilizadores seletivos para os tecidos investigados. As vantagens da utilização são: boa visualização da área acometida, forte sinal de fluorescência, possuem espectros de excitação e emissão bem conhecidos e não causam falsos positivos, sendo assim, mais sensíveis e específicos (ROBERTS-THOMSON et al., 2010; BORISOVA et al., 2011). Como desvantagens, tem-se os custos relacionados com o processo de registro e aprovação dos PS utilizados, e possíveis efeitos colaterais como danos vasculares levando a estase sanguínea, toxicidade celular e leve depressão do sistema imune (DACOSTA et al., 2007; SOUMYA et al., 2014).

Para o sucesso do diagnóstico é importante conhecer o espectro de excitação e absorção do fluoróforo utilizado, seu tempo de vida de fluorescência e a concentração a ser utilizada (ANDERSSON-ENGELS et al., 1997). Não existe uma definição de cálculo da dose do PS, porém a estimativa da dose necessária deve ser efetuada com base no intervalo de iluminação necessário versus tempo de vida de fluorescência do PS, tempo de distribuição do PS pelos tecidos e tempo de excreção (HUANG et al., 2008; SOUMYA et al., 2014).

ANDRADE et al. (2014) realizaram um estudo utilizando duas concentrações do fotossensibilizador ALA (cinco e dez \%), e as imagens foram capturadas em diferentes tempos após a aplicação do PS (15,30, 45 e 60 minutos) para descobrirem qual seria o protocolo ideal para diagnosticar as neoplasias. Eles chegaram à conclusão que o tempo ideal de espera após a aplicação do PS é de 60 minutos ou mais, pois a fluorescência (vermelha) apresentada pela neoplasia foi maior após este período. A concentração do PS não pode ser avaliada, pois as lesões apresentavam crostas que não foram removidas antes do estudo, levando ao acúmulo do PS nas bordas da lesão, mas os autores acreditam que a menor concentração já é suficiente para produzir uma fluorescência característica. 
Para medir a fluorescência emitida pode-se utilizar a espectroscopia de fluorescência, que consiste na medição e análise dos vários recursos que estão relacionados com o rendimento quântico de fluorescência e/ou tempo de vida de uma molécula biológica (BROWN, 1985). O rendimento quântico é a razão entre o número de moléculas excitadas na reação, pelo número total de fótons absorvidos. A vida útil é definida como o tempo médio da molécula no estado excitado antes de retornar ao estado fundamental (RAMANUJAM, 2000).

A fluorescência por imagem de campo amplo (como utilizada nos endoscópios) é outra técnica utilizada para visualizar a fluorescência dos tecidos, porém, esta não é pontual como a espectroscopia, apresenta apenas as imagens de campo, ou seja, a diferença de fluorescência entre os tecidos normais e anormais. Dessa forma, é utilizada para detectar lesões ocultas e/ou delimitar as margens das lesões (POH et al., 2006; BLANCO et al., 2015).

Esses aparelhos utilizados para visualização da fluorescência são constituídos basicamente por dois sistemas: o sistema de excitação das moléculas, ou seja, um sistema de iluminação, como lasers, lâmpadas ou LEDs; e um sistema de detecção associado a filtros, que irá revelar o sinal de fluorescência obtido da amostra ( $\mathrm{POH}$ et al., 2006). O diagnóstico fotodinâmico ainda não é utilizado em todas as especialidades médicas, porém algumas já se beneficiam com a alta especificidade e sensibilidade, dentre elas a oncologia, odontologia e gastroenterologia, que serão abordadas a seguir.

\section{- Oncologia}

O diagnóstico fotodinâmico é amplamente utilizado na medicina para diagnosticar neoplasias, sejam cutâneas ou em órgãos internos. Esta técnica possui três principais aplicações: (1) Diferenciar neoplasias benignas de neoplasias malignas sem recorrer à biópsia histológica; (2) auxiliar na demarcação do tecido saudável e do tecido doente; (3) Avaliar a resposta do tratamento realizado ( FRITSCH \& RUZICKA, 2006;IKEURA et al, 2015; BLANCO et al., 2015; NAMIKAWA et al., 2015).

A detecção da neoplasia em estágios iniciais permite a rápida remoção do tumor e a determinação precoce do protocolo de tratamento. Assim, a autofluorescência e o uso de fluoróforos exógenos permitem detectar os primeiros estágios de câncer, não só em procedimentos endoscópicos, mas também sobre a pele e em órgãos genitais (SIERON et al., 2013).

O fotodiagnóstico pode ser realizado por diferentes técnicas dependendo do local da lesão. Na pele a técnica é realizada da seguinte maneira: a lesão é limpa com água e sabão, se houverem crostas, a retirada é necessária. Logo em seguida é aplicado diretamente na lesão um creme que contém em sua composição fluoróforos (geralmente o ALA ou Photofrin®). Aguarda-se por volta de três horas após a aplicação para que o fotossensibilizador acumule-se nos tecidos-alvo, após esse período a lesão é irradiada no comprimento de onda específico do fotossensibilizador utilizado, e a fluorescência característica da neoplasia pode ser visualizada caso esta esteja presente. Além disso, a lesão investigada pode apresentar vários níveis de intensidade de fluorescência, permitindo ao médico estimar o estadiamento da neoplasia, além de permitir uma análise de profundidade, largura e extensão da lesão (ALLISON \& SIBATA, 2008; GAMBICHLER et al., 2008; DRAKAKI et al., 2014). 
No diagnóstico de neoplasias internas, utiliza-se um endoscópio com luz azul para visualizar as estruturas de interesse, muitas vezes o diagnóstico é realizado pela autofluorescência do tecido, porém, quando necessário, utiliza-se fluoróforos exógenos, que podem ser administrados de duas a três horas antes do procedimento por via oral, endovenosa ou intraperitoneal (AHMAD et al., 2012).

Em neoplasias gástricas, utiliza-se um endoscópio que possua um laser acoplado, permitindo assim, a diferenciação de lesões malignas e benignas por meio de uma endoscopia simples e pouco invasiva (ISOMOTO et al., 2015; NAKAMURA et al., 2015; KISHI et al., 2014; NAKAMURA \& OINUMA, 2014; NAMIKAWA et al., 2015).

No diagnóstico de câncer de bexiga, o fotodiagnóstico vem sendo utilizado amplamente com o intuito de identificar o tumor durante a endoscopia e auxiliar na demarcação das bordas cirúrgicas, aumentando as chances de ressecção total da neoplasia, reduzindo as taxas de recorrência (GAKIS et al., 2015; LEE et al., 2015; LYKKE et al., 2015; MARIAPPAN et al., 2015; ZLATEV et al., 2015).

No sistema nervoso central, essa técnica vem sendo utilizada principalmente para auxiliar na coleta de amostras para biópsia, pois mostra o local exato da neoplasia (YAMAMOTO et al., 2015), e permite também, uma melhor visualização das bordas cirúrgicas na resecção de neoplasias como o linfoma primário (PCNSL) e gliomas (WIDHALM et al., 2010; EWELT et al., 2011; ROESSLER et al., 2012; COBURGER et al., 2014; YAMADA et al., 2015).

GAHLEN et al. (2001) realizaram um estudo utilizando o fotossensibilizador ALA, e compararam as vias intraperitoneal e endovenosa no diagnóstico de várias neoplasias. A via intraperitoneal apresentou fluorescência positiva em $100 \%$ dos casos, enquanto a via endovenosa em apenas $28 \%$ dos casos, mostrando que a via intraperitoneal apresenta maior sensibilidade diagnóstica.

SIERON et al. (2013) realizaram o exame histopatológico de biópsia excisada do esôfago de uma paciente humana de 71 anos de idade, porém, o exame não detectou a presença de tecidos malignos. Resolveram então, realizar um diagnóstico fotodinâmico utilizando o fotossensibilizador ALA (Levulan®) e endoscopia com luz fluorescente. Este exame mostrou uma neoplasia de esôfago, que foi confirmada por um novo exame histopatológico realizado com a biopsia guiada pela fluorescência.

$\mathrm{KISH}$ et al. (2014) utilizaram o fotossensibilizador ALA no diagnóstico fotodinâmico de metástases peritoniais. A laparoscopia diagnóstica foi realizada em 52 pacientes com cancêr gástrico avançado, sendo utilizada a laparoscopia comum com luz branca e a laparoscopia com ALA nos mesmos pacientes. Deste total, 24 pacientes (46\%) não tiveram nenhuma evidência macroscópica de metástases peritoniais no exame de laparoscopia comum, enquanto na laparoscopia com ALA, foi possível diagnosticar cinco pacientes destes 24 doentes (21\%) que não foram diagnosticados no exame de rotina, mostrando que a laparoscopia com o fotossensibilizador ALA possui uma maior sensibilidade para a deteç̧ão de metástases peritoniais.

FUKUHARA et al. (2015), realizaram um estudo em 52 pacientes com câncer de próstata, a fim de detectar as margens cirúrgicas positivas, pelo mapeamento de fluorescência vermelha nas células cancerosas da próstata, durante a prostatectomia com o auxilio da laparoscopia com ALA. Destes 52 pacientes, 18 receberam a prostatectomia convencional e 34 pacientes a prostatectomia com mapeamento pelo ALA. A sensibilidade e especificidade foram de $75 \%$ na cirurgia 
convencional e de $87,3 \%$ na cirurgia com ALA, mostrando a melhor eficiência com a utilização do fotossensibilizador.

TANABE et al. (2004) realizaram um estudo em cães e gatos utilizando um novo fotossensibilizador, PAD-S31 e avaliaram a eficácia. Utilizaram animais com neoplasias naturais, sendo 18 cães e dois gatos, e todos os animais que possuíam neoplasias malignas haviam sido diagnosticados positivos pela histopatologia previamente. O fotossensibilizador foi injetado nos tumores dos animais e expostos à luz (402 nm). A fluorescência foi detectada visualmente através da utilização de laser de argônio em 14 dos 15 tumores malignos. E os tumores benignos não fluoresceram, mostrando a grande sensibilidade do teste e eficácia deste fotossensibilizador.

\section{- Odontologia}

A fluorescência induzida pela utilização de lasers pode ser usada para detectar e diagnosticar a cárie dentária, cálculos e biofilmes bacterianos. $O$ diagnóstico fotodinâmico é uma excelente ferramenta de diagnóstico que veio para substituir as ferramentas imprecisas utilizadas anteriormente, como a inspeção visual e as radiografias (SHAKIBAIE et al., 2011; CARVALHO, 2014; MELO et al., 2015). Essa técnica ganhou espaço por ser uma terapia minimamente invasiva, que permite a detecção precoce de lesões, avaliação dos possíveis fatores de risco e acompanhamento do tratamento (EROL et al., 2014).

A cárie dentária apresenta uma autofluorescência característica quando excitada no espectro de $407 \mathrm{~nm}$. O tecido dentário saudável não apresenta bandas de emissão no vermelho, assim, somente o tecido cariado irá fluorescer. Os espectros de excitação e emissão das lesões de cárie são típicos de porfirinas, principalmente da protoporfirina IX, a possível fonte de porfirina no tecido cariado é a biossíntese bacteriana que ocorre no local (KONIG et al., 1998).

HAMISHAKI et al. (2014) realizaram um estudo comparativo entre a inspeção visual realizada por dentistas com experiência clínica e um aparelho de fluorescência a laser (DIAGNOdent®) para diagnosticar a cárie dentária secundária. Para isso, utilizaram 40 pacientes com lesões de cáries, e compararam o diagnóstico realizado entre eles. Como resultado obtiveram uma maior precisão diagnóstica do aparelho DIAGNOdent $\AA$, sendo que o mesmo identificou cárie em 99\% dos pacientes estudados.

Outro aparelho utilizado para avaliação quantitativa de lesões de cárie, placa bacteriana, atividade bacteriana e cálculos é o QLFTM, desenvolvido por G. K. Stookey e colaboradores em convênio com a empresa Inspektor Research Systems. O QLFTM permite a visualização da formação de biofilmes bacterianos facilitando o tratamento precoce (STOOKEY, 2004, 2005).

A fluorescência também é utilizada como um guia para a escavação da cavidade cariada. Ao longo do tratamento é feita a visualização do tecido dental, a fim de verificar se ainda há tecido com cárie no dente tratado, ou se foi removido na totalidade (EROL et al., 2014). Pode ser utilizada ainda, na inativação fotodinâmica de microrganismos relacionados à cárie dentária e placas, utilizando o mesmo aparelho do diagnóstico, modificando somente o protocolo de utilização, como, por exemplo, o comprimento de onda (GUGLIELMI CDE et al., 2011; NAGATA et al., 2012; NOGUEIRA et al., 2013; SANTIN et al., 2014). 


\section{- Gastroenterologia}

A endoscopia de fluorescência com processamento digital das imagens representa uma revolução no diagnóstico do trato digestivo, pois permite obter os resultados de forma rápida, não invasiva, com visualização de pequenas lesões e com alta sensibilidade e especificidade (SIERON-STOLTNY et al., 2012; NAKAMURA et al., 2015).

Os papilomas esofágicos e o Esôfago de Barret são lesões benignas, mas possuem relevância clínica por serem consideradas lesões pré-malignas, que podem evoluir para displasia e câncer de esôfago do tipo adenocarcinoma (KOPPERT et al., 2005). O Esôfago de Barrett ou síndrome de Barrett consiste na metaplasia das células da porção inferior do esôfago, devido à presença de refluxo gastroesofágico crônico, levando ao desconforto do paciente por episódios de refluxo e pirose (STEIN \& SIEWERT, 1993). O diagnóstico tradicional é a biopsia com a visualização de células metaplásicas, porém, com o diagnóstico fotodinâmico é possível realizar o exame de forma rápida e pouco invasiva (BOERWINKEL et al., 2014; JIN et al., 2015). O exame é realizado com um endoscópio de fluorescência, que por meio da fluorescência endógena das células metaplásicas mostram o local acometido pela doença (SIERON et al., 2013; STURM \& WANG, 2015).

POLSACHEV et al. (1992) indicam o uso do diagnóstico fotodinâmico para diferenciar doenças gástricas como a gastrite e úlcera, de neoplasias malignas. Eles realizaram um estudo com 490 pacientes, que tinham como diagnóstico presuntivo gastrite crônica, úlcera gástrica e pólipos. No diagnóstico fluorescente dos pólipos, $91,5 \%$ dos casos foram concordantes com as análises do estudo histológico. Já a análise de fluorescência para diagnosticar a doença ulcerosa foi igual a $87,5 \%$ e $86 \%$ em gastrite crônica quando comparados à biopsia.

É importante lembrar que tecidos com inflamações e neovascularizações também apresentam autofluorescência, por isso, deve-se ter o cuidado ao visualizar lesões indicativas de câncer, e associar diferentes técnicas para realizar um diagnóstico definitivo (SAETTI et al., 2007).

\section{- Outras Aplicações}

O diagnóstico fotodinâmico também pode ser utilizado com sucesso para a classificação de risco da rejeição de enxertos de pele, por meio do monitoramento dos espectros de fluorescência de monômeros como o cloro alumino ftalocianina (ALPC) (VASILCHENKO et al., 2010). O ALPC é um fotossensibilizador que fluoresce na forma molecular, mas sob a forma de nanopartículas isso não acontece, dessa forma, utiliza-se nanopartículas hidrofóbicas como carreadoras do ALPC para o interior de macrófagos e neutrófilos. Uma vez no interior dessas células elas irão fluorescer ao serem irradiadas, mostrando o local de inflamação (ABDELMOTTALEB et al., 2012; BREYMAYER et al., 2014). Desta forma, os transplantes de pele que apresentam uma alta intensidade de fluorescência, indicam um processo inflamatório, enquanto os transplantes saudáveis apresentam fluorescência com baixa intensidade (NGUYEN et al., 2012; BREYMAYER et al., 2014).

Outra possível aplicação é no diagnóstico de fungos, TURNER et al. (2014) utilizaram três diferentes fontes de luz para captarem a autofluorescência emitida por fungos da espécie Pseudogymnoascus destructans. Esses fungos causam a síndrome do nariz branco, uma doença emergente que acomete morcegos e ocasiona altas taxas de mortalidade. Os autores demonstraram que a luz ultravioleta 
no comprimento de onda de $366-385 \mathrm{~nm}$ provoca uma fluorescência laranjaamarelada no local onde se encontram os fungos. Eles compararam a técnica de fluorescência com a técnica padrão ouro (histopatológico), sendo que a fluorescência apresentou sensibilidade de 98,8\%, mostrando ser um diagnóstico bastante sensível, específico, barato e rápido.

MASILAMANI et al. (2014) relataram o uso do diagnóstico fotodinâmico no diagnóstico da Malária. Esta doença é geralmente detectada pelo esfregaço sanguíneo (gota espessa), uma técnica com média sensibilidade, por isso, os autores investigaram o uso do fotodiagnóstico como uma alternativa ao teste padrão ouro. Eles utilizaram um espectrofluorímetro para medir a autofluorescência advinda de um conjunto de biomoléculas do plasma sanguíneo como a tirosina, triptofano, $\mathrm{NADH}$, dinucleótido de flavina adenina (FAD) e porfirinas advindas das hemoglobinas, de 14 pacientes com malária. Concluíram que o fotodiagnóstico apresentou sensibilidade e especificidade superiores a $90 \%$ com base nas características espectrais dos componentes do sangue. Provando que essa técnica possui um grande potencial para ser utilizada como um procedimento alternativo de diagnóstico para a malária, uma vez que a instrumentação envolvida é portátil e de baixo custo.

\section{CONSIDERAÇÕES FINAIS}

O diagnóstico laboratorial de uma doença é uma ferramenta essencial para o médico veterinário, pois, através de resultados precisos, o melhor protocolo terapêutico pode ser estabelecido. Quanto mais precoce ocorrer o diagnóstico, melhor será o tratamento e prognóstico do animal. Dessa forma, o diagnóstico fotodinâmico surge como uma importante ferramenta diagnóstica, sendo rápida, de fácil realização, não invasiva, seletiva e sensível.

A técnica de fluorescência possui um enorme potencial de utilização em uma ampla variedade de situações clínicas, porém cada caso deve ser tratado de maneira ímpar, pois a técnica irá variar de acordo com a aplicação. Cada fotossensibilizador possui um espectro de excitação e emissão diferentes, e possuem seletividade por diferentes tecidos, assim, cada aplicação da técnica deve ser estudada antes da aplicação.

$\mathrm{Na}$ Medicina é uma técnica amplamente utilizada, principalmente no diagnóstico do câncer, no auxilio da demarcação entre o tecido saudável e o tecido doente e na avaliação da resposta ao tratamento realizado. Também é bastante utilizada na identificação de doenças bucais, como a periodontite, cáries e identificação de biofilmes bacterianos, sendo uma ferramenta útil a ser incorporada na medicina veterinária, oferecendo um diagnóstico seguro e evitando extrações dentárias desnecessárias.

$\mathrm{Na}$ Medicina Veterinária esta técnica é utilizada apenas no diagnóstico de úlcera de córnea com a utilização da fluoresceína e no diagnóstico da dermatofitose com o uso da luz de Wood. Porém, essa técnica se mostra bastante promissora e poderá ser aplicada em diversas áreas, desde a clínica até a tecnologia de alimentos. Mas para que essa técnica seja incorporada na rotina, estudos são necessários para encontrarem os protocolos ideais para cada aplicação. 


\section{REFERÊNCIAS}

ABDEL-MOTTALEB, M. M. A.; MOULARI, B.; BedUNEAU, A.; PELLEQUER, Y., LAMPRECHT, A. Nanoparticles enhance therapeutic outcome in inflamed skin therapy. European Journal of Pharmaceutics and Biopharmaceutics, v. 82, n. 1, p. 151-157, 2012. ISSN 0939-6411.

AHMAD, S.; ABOUMARZOUK, O.; SOMANI, B.; NABI, G.; KATA, S. G. Oral 5aminolevulinic acid in simultaneous photodynamic diagnosis of upper and lower urinary tract transitional cell carcinoma - a prospective audit. BJU Int, v. 110, n. $11 \mathrm{Pt}$ B, p. E596-600, Dec 2012. ISSN 1464-4096.

ALLISON, R. R.; MOTA, H. C.; BAGNATO, V. S.; SIBATA, C. H. Bio-nanotechnology and photodynamic therapy-State of the art review. Photodiagnosis and Photodynamic Therapy, v. 5, n. 1, p. 19-28, 2008. ISSN 1572-1000..

ALLISON, R. R.; SIBATA, C. H. Photodiagnosis for cutaneous malignancy: a brief clinical and technical review. Photodiagnosis Photodyn Ther, v. 5, n. 4, p. 247-50, Dec 2008. ISSN 1572-1000.

ANDERSSON-ENGELS, S.; KLINTEBERG, C.; SVANBERG, K.; SVANBERG, S. In vivo fluorescence imaging for tissue diagnostics. Phys Med Biol, v. 42, n. 5, p. 81524, May 1997. ISSN 0031-9155.

ANDRADE, C. T.; VOLLET-FILHO, J. D.; SALVIO, A. G.; BAGNATO, V. S.; KURACHI, C. Identification of skin lesions through aminolaevulinic acid-mediated photodynamic detection. Photodiagnosis Photodyn Ther, v. 11, n. 3, p. 409-15, Sep 2014. ISSN 1572-1000.

BARON, E. D.; MALBASA, C. L.; SANTO-DOMINGO, D.; FU, P.; MILLER, J. D.; HANNEMAN, K. K.; HSIA, A. H.; OLEINICK, N. L.; COLUSSI, V. C.; COOPER, K. D. Silicon phthalocyanine $(\mathrm{Pc} 4)$ photodynamic therapy is a safe modality for cutaneous neoplasms: results of a phase 1 clinical trial. Lasers Surg Med, v. 42, n. 10, p. 72835, Dec 2010. ISSN 0196-8092.

BLANCO, K. C.; MORIYAMA, L. T.; INADA, N. M.; KURACHI, C.; SALVIO, A. G.; LEITE, E. J. D. S.; MENEZES, P. F. C.; BAGNATO, V. S. Fluorescence Guided PDT for Optimization of Skin Cancer Treatment. Frontiers in Physics, v. 3, 2015. ISSN 2296-424X.

BOERWINKEL, D. F.; SHARIFF, M. K.; DI PIETRO, M.; HOLZ, J. A.; AALDERS, M. C.; CURVERS, W. L.; FITZGERALD, R. C.; BERGMAN, J. J. Fluorescence imaging for the detection of early neoplasia in Barrett's esophagus: old looks or new vision Eur J Gastroenterol Hepatol, v. 26, n. 7, p. 691-8, Jul 2014. ISSN 0954-691x.

BORISOVA, E.; VLADIMIROV, B.; IVANOVA, R; AVRAMOV, L. Light-Induced fluorescence techniques for gastrointestinal tumour detection. New Techniques in 
Gastrointestinal Endoscopy,"(Oliviu Pascu and Andrada Seicean Ed.), InTech, Rijeka, v. 14, p. 231-252, 2011.

BORRONI, R. G.; BARRUSCOTTI, S.; CARUGNO, A.; BARBACCIA, V.; ARBUSTINI, E.; BRAZZELLI, V. Usefulness of in vivo photodiagnosis for the identification of tumor margins in recurrent basal cell carcinoma of the face. Photodermatology, Photoimmunology \& Photomedicine, v. 31, n. 4, p. 195-201, 2015. ISSN 1600-0781.

BOSE, B.; DUBE, A. Photodynamic efficacy of chlorin p6: A pH dependent study in aqueous and lipid environment. Journal of Photochemistry and Photobiology B: Biology, v. 93, n. 1, p. 32-35, 10/16/ 2008. ISSN 1011-1344.

BRACKMANN, U. Laser Dyes. Göttingen (Germany): Lambda Physik AG. D37079, 2000.

BRAGA, G.; APARICIO, J. L.; VILSINSKI, B. H.; TESSARO, A. L.; GEROLA, A. P.; HIOKA, N.; CAETANO, W. Autoagregação da 5,10,15,20-tetrakis(4metoxifenil)porfirina (tmpp): estudos espectroscópicos e análises multivariadas. Química Nova, v. 37, p. 648-652, 2014. ISSN 0100-4042.

BREYMAYER, J.; RUCK, A.; RYABOVA, A. V.; LOSCHENOV, V. B.; STEINER, R. $W$. Fluorescence investigation of the detachment of aluminum phthalocyanine molecules from aluminum phthalocyanine nanoparticles in monocytes/macrophages and skin cells and their localization in monocytes/macrophages. Photodiagnosis Photodyn Ther, v. 11, n. 3, p. 380-90, Sep 2014. ISSN 1572-1000.

BROWN, S. B. Biological spectroscopy: By I D Campbell and R A Dwek. pp 404. Addison-Wesley, Wokingham, ISBN 0-8053-1847-X and 0-8053-1849-6. Biochemical Education, v. 13, n. 2, p. 93-93, 1985. ISSN 1879-1468.

CARVALHO, J. C. Caries Process on Occlusal Surfaces: Evolving Evidence and Understanding. Caries Research, v. 48, n. 4, p. 339-346, 2014. ISSN 0008-6568.

CHEUNG, G.; SAHAI, A.; BILLIA, M., DASGUPTA, P.; KHAN, M. S. Recent advances in the diagnosis and treatment of bladder cancer. BMC Medicine, v. 11, p. 13-13, 2013. ISSN 1741-7015.

CHOWDHARY, R. K.; SHARIF, I.; CHANSARKAR, N.; DOLPHIN, D.; RATKAY, L.; DELANEY, S. AND MEADOWS. H. Correlation of photosensitizer delivery to lipoproteins and efficacy in tumor and arthritis mouse models; comparison of lipidbased and Pluronic P123 formulations. J Pharm Pharm Sci, v. 6, n. 2, p. 198-204, May-Aug 2003. ISSN 1482-1826.

COBURGER, J.; ENGELKE, J.; SCHEUERLE, A.; THAL, D. R.; HLAVAC, M.; WIRTZ, C. R.; KONIG, R. Tumor detection with 5-aminolevulinic acid fluorescence and Gd-DTPA-enhanced intraoperative MRI at the border of contrast-enhancing lesions: a prospective study based on histopathological assessment. Neurosurg Focus, v. 36, n. 2, p. E3, Feb 2014. ISSN 1092-0684. 
DACOSTA, R. S.; WILSON, B. C.; MARCON, N. E. Fluorescence and spectral imaging. The Scientific World Journal, v. 7, p. 2046-2071, 2007.

DEROSA, M. C.; CRUTCHLEY, R. J. Photosensitized singlet oxygen and its applications. Coordination Chemistry Reviews, v. 233-234, n. 0, p. 351-371, 11/1/ 2002. ISSN 0010-8545.

DOLPHIN, D.; TRAYLOR, T. G.; XIE, L. Y. Polyhaloporphyrins: $\square$ Unusual Ligands for Metals and Metal-Catalyzed Oxidations. Accounts of Chemical Research, v. 30, n. 6, p. 251-259, 1997. ISSN 0001-4842.

DOUGHERTY, T. J.; GRINDEY, G. B.; FIEL, R.; WEISHAUPT, K. R.; BOYLE, D. G. Photoradiation therapy. II. Cure of animal tumors with hematoporphyrin and light. $\mathbf{J}$ Natl Cancer Inst, v. 55, n. 1, p. 115-21, Jul 1975. ISSN 0027-8874.

DRAKAKI, E.; DESSINIOTI, C.; STRATIGOS, A. J.; SALAVASTRU, C.; ANTONIOU, C. Laser-induced fluorescence made simple: implications for the diagnosis and follow-up monitoring of basal cell carcinoma. J Biomed Opt, v. 19, n. 3, p. 30901, Mar 2014. ISSN 1083-3668.

EROL, S.; KAMAK, H.; ERTEN, H. Evaluation of caries dentin using light-induced fluorescence: a case report. J Clin Diagn Res, v. 8, n. 1, p. 297-8, Jan 2014. ISSN 2249-782X.

EWELT, C.; FLOETH, F. W.; FELSBERG, J.; STEIGER, H. J.; SABEL, M.; LANGEN, K. J.; STOFFELS, G.; STUMMER, W. Finding the anaplastic focus in diffuse gliomas: the value of Gd-DTPA enhanced MRI, FET-PET, and intraoperative, ALAderived tissue fluorescence. Clin Neurol Neurosurg, v. 113, n. 7, p. 541-7, Sep 2011. ISSN 0303-8467.

EWING, G. W. Instrumental methods of chemical analysis. McGraw-Hill Companies, 1975. ISBN 9780070198531.

FILIP, M.; IORDACHE, S.; SAFTOIU, A.; CIUREA, T. Autofluorescence imaging and magnification endoscopy. World journal of gastroenterology: WJG, v. 17, n. 1, p. 9, 2011.

FOOTE, C. S. Mechanisms of photosensitized oxidation. There are several different types of photosensitized oxidation which may be important in biological systems. Science, v. 162, n. 3857, p. 963-70, Nov 29 1968. ISSN 0036-8075.

FRACKOWIAK, D. The Jablonski diagram. Journal of Photochemistry and Photobiology B: Biology, v. 2, n. 3, p. 399, 1988/11/01 1988. ISSN 1011-1344.

FRITSCH, C.; RUZICKA, T. Fluorescence diagnosis and photodynamic therapy in dermatology from experimental state to clinic standard methods. J Environ Pathol Toxicol Oncol, v. 25, n. 1-2, p. 425-39, 2006. ISSN 0731-8898. 
FUKUHARA, H.; INOUE, K.; KURABAYASHI, A.; FURIHATA, M.; SHUIN, T. Performance of 5-aminolevulinic-acid-based photodynamic diagnosis for radical prostatectomy. BMC Urology, London, v. 15, p. 78, 2015. ISSN 1471-2490.

GAHLEN, J.; PIETSCHMANN, M.; PROSST, R. L.; HERFARTH, C. Systemic vs local administration of delta-aminolevulinic acid for laparoscopic fluorescence diagnosis of malignant intra-abdominal tumors. Experimental study. Surg Endosc, v. 15, n. 2, p. 196-9, Feb 2001. ISSN 0930-2794.

GAKIS, G.; NGAMSRI, T.; RAUSCH, S.; MISCHINGER, J.; TODENHÖFER, T.; SCHWENTNER, C.; SCHMID, M.; HASSAN, F.-S.; RENNINGER, M.; STENZL, A. Fluorescence-guided bladder tumour resection: impact on survival after radical cystectomy. World Journal of Urology, p. 1-9, 2015/01/17 2015. ISSN 0724-4983.

GAMBICHLER, T.; MOUSSA, G.; ALTMEYER, P. A pilot study of fluorescence diagnosis of basal cell carcinoma using a digital flash light-based imaging system. Photodermatol Photoimmunol Photomed, v. 24, n. 2, p. 67-71, Apr 2008. ISSN 0905-4383.

GUGLIELMI CDE, A.; SIMIONATO, M. R.; RAMALHO, K. M.; IMPARATO, J. C.; PINHEIRO, S. L.; LUZ, M. A. Clinical use of photodynamic antimicrobial chemotherapy for the treatment of deep carious lesions. J Biomed Opt, v. 16, n. 8, p. 088003, Aug 2011. ISSN 1083-3668.

GUYON, L.; ASCENCIO, M.; COLLINET, P.; MORDON, S. Photodiagnosis and photodynamic therapy of peritoneal metastasis of ovarian cancer. Photodiagnosis Photodyn Ther, v. 9, n. 1, p. 16-31, Mar 2012. ISSN 1572-1000.

HAMISHAKI, K. S.; CHINIFORUSH, N.; MONZAVI, A.; KHAZARAZIFARD, M. J. An in vivo comparison of two diagnostic methods in secondary caries detection. $\mathbf{J}$ Dent (Tehran), v. 11, n. 1, p. 17-21, Jan 2014. ISSN 1735-2150.

HUANG, Z.; XU, H.; MEYERS, A. D.; MUSANI, A. I.; WANG, L.; TAGG, R.; BARQAWI, A. B.; CHEN, Y. K. Photodynamic therapy for treatment of solid tumors-potential and technical challenges. Technol Cancer Res Treat, v. 7, n. 4, p. 309-20, Aug 2008. ISSN 1533-0346.

KEURA, T.; TAKAOKA, M.; UCHIDA, K.; SHIMATANI, M.; MIYOSHI, H.; KATO, K.; OHE, C.; UEMURA, Y.; KAIBORI, M.; KWON, A. H.; OKAZAKI, K.. Fluorescence cytology with 5-aminolevulinic acid in EUS-guided FNA as a method for differentiating between malignant and benign lesions (with video). Gastrointestinal Endoscopy, v. 81, n. 6, p. 1457-1462, 2015.

INGLE, J. D.; CROUCH, S. R. Spectrochemical Analysis. Prentice Hall, 1988. ISBN 9780138268763.

INOUE, Y.; TANAKA, R.; KOMEDA, K.; HIROKAWA, F.; HAYASHI, M.; UCHIYAMA, K. Fluorescence Detection of Malignant Liver Tumors using 5-Aminolevulinic AcidMediated Photodynamic Diagnosis: Principles, Technique, and Clinical Experience. 
World Journal of Surgery, v. 38, n. 7, p. 1786-1794, 2014/07/01 2014. ISSN 03642313.

ISOMOTO, H.; NANASHIMA, A.; SENOO, T.; OGIWARA, K.; HASHISAKO, M.; OHNITA, K.; YAMAGUCHI, N.; KUNIZAKI, M.; HIDAKA, S.; FUKUDA, H.; ISHII, H.; MATSUSHIMA, K.; MINAMI, H.; AKAZAWA, Y.; TAKESHIMA, F.; FUKUOKA, J.; NAGAYASU, T.; NAKAO, K. In vivo fluorescence navigation of gastric and upper gastrointestinal tumors by 5-aminolevulinic acid mediated photodynamic diagnosis with a laser-equipped video image endoscope. Photodiagnosis and Photodynamic Therapy, v. 12, n. 2, p. 201-208, 2015.

JIANG, Z.; SHAO, J.; YANG, T.; WANG, J.; JIA, L. Pharmaceutical development, composition and quantitative analysis of phthalocyanine as the photosensitizer for cancer photodynamic therapy. Journal of Pharmaceutical and Biomedical Analysis, v. 87, p. 98-104, 1/18/ 2014. ISSN 0731-7085.

JIN, N. Y.; WANG, K.; WEI, S. Q.; LI, Y. Q.; WANG, H. W.; XU, L. M.; SHI, J. P. Diagnostic value of autofluorescence imaging combined with narrow band imaging in intraepithelial neoplasia of Barrett's esophagus. J buon, v. 20, n. 2, p. 399-405, MarApr 2015. ISSN 1107-0625.

KISHI, K.; FUJIWARA, Y.; YANO, M.; MOTOORI, M.; SUGIMURA, K.; OHUE, M.; NOURA, S.; MARUBASHI, S.; TAKAHASHI, H.; SAKON, M. Diagnostic Laparoscopy with 5-Aminolevulinic-Acid-Mediated Photodynamic Diagnosis Enhances the Detection of Peritoneal Micrometastases in Advanced Gastric Cancer. Oncology, v. 87, n. 5, p. 257-265, 2014. ISSN 0030-2414.

KONIG, K.; FLEMMING, G.; HIBST, R. Laser-induced autofluorescence spectroscopy of dental caries. Cell Mol Biol (Noisy-le-grand), v. 44, n. 8, p. 1293300, Dec 1998. ISSN 0145-5680.

KOPPERT, L. B.; WIJNHOVEN, B. P.; VAN DEKKEN, H.; TILANUS, H. W.; DINJENS, W. The molecular biology of esophageal adenocarcinoma. J Surg Oncol, v. 92, n. 3, p. 169-90, Dec 1 2005. ISSN 0022-4790.

KRAMER-MAREK, G.; SERPA, C.; SZURKO, A.; WIDEL, M.; SOCHANIK, A.; SNIETURA, M.; KUS, P.; NUNES, R. M.; ARNAUT, L. G.; RATUSZNA, A. Spectroscopic properties and photodynamic effects of new lipophilic porphyrin derivatives: efficacy, localisation and cell death pathways. J Photochem Photobiol B, v. 84, n. 1, p. 1-14, Jul 3 2006. ISSN 1011-1344.

LAKOWICZ, J. R. Principles of Fluorescence Spectroscopy. Springer, 2007. ISBN 9780387463124.

LEE, J. Y.; CHO, K. S.; KANG, D. H.; JUNG, H. D.; KWON, J. K.; OH, C. K.; HAM, W. S.; CHOI, Y. D. A network meta-analysis of therapeutic outcomes after new image technology-assisted transurethral resection for non-muscle invasive bladder cancer: 5-aminolaevulinic acid fluorescence vs hexylaminolevulinate fluorescence vs narrow band imaging. BMC Cancer, London, v. 15, p. 566, 2015. ISSN 1471-2407. 
LEHNINGER, A.; NELSON, D.; COX, M. Lehninger Principles of Biochemistry. W. H. Freeman, 2008.

LYKKE, M. R.; NIELSEN, T. K.; EBBENSGAARD, N. A.; ZIEGER, K. Reducing recurrence in non-muscle-invasive bladder cancer using photodynamic diagnosis and immediate post-transurethral resection of the bladder chemoprophylaxis. Scandinavian Journal of Urology, v. 49, n. 3, p. 230-236, 2015. ISSN 2168-1805.

MARIAPPAN, P.; RAI, B.; EL-MOKADEM, I.; ANDERSON, C. H.; LEE, H.; STEWART, S.; DONAT, R. Real-life Experience: Early Recurrence With Hexvix Photodynamic Diagnosis-assisted Transurethral Resection of Bladder Tumour vs Good-quality White Light TURBT in New Non-muscle-invasive Bladder Cancer. Urology, v. 86, n. 2, p. 327-331, 2015. ISSN 0090-4295.

MASILAMANI, V.; DEVANESAN, S.; RAVIKUMAR, M.; PERINBAM, K.; ALSALHI, M.; PRASAD, S.; PALLED, S.; GANESH, K.; ALSAEED, A. L. Fluorescence spectral diagnosis of malaria inverted question mark a preliminary study. Diagn Pathol, v. 9, n. 1, p. 182, Oct 17 2014. ISSN 1746-1596.

MELO, M.; PASCUAL, A.; CAMPS, I.; DEL CAMPO, Á. In vivo study of different methods for diagnosing pit and fissure caries. Journal of Clinical and Experimental Dentistry, v. 7, n. 3, p. e387-e391, 2015. ISSN 1989-5488.

MIRONOV, A. F.; NIZHNIK, A. N.; NOCKEL, A. Y. Hematoporphyrin derivatives: an oligomeric composition study. J Photochem Photobiol B, v. 4, n. 3, p. 297-306, Jan 1990. ISSN 1011-1344.

MOGHISSI, K.; STRINGER, M. R.; DIXON, K. Fluorescence photodiagnosis in clinical practice. Photodiagnosis Photodyn Ther, v. 5, n. 4, p. 235-7, Dec 2008. ISSN 1572-1000.

MONTANARI, F. Biomimetic oxygenations catalyzed by metalloporphyrins and metalloporphinoids bearing co-catalytic functions. Pure and Applied Chemistry. 66: 1519 p. 1994.

NAGATA, J. Y.; HIOKA, N.; KIMURA, E.; BATISTELA, V. R.; TERADA, R. S.; GRACIANO, A. X.; BAESSO, M. L.; HAYACIBARA, M. F. Antibacterial photodynamic therapy for dental caries: evaluation of the photosensitizers used and light source properties. Photodiagnosis Photodyn Ther, v. 9, n. 2, p. 122-31, Jun 2012. ISSN 1572-1000.

NAKAMURA, M.; NISHIKAWA, J.; HAMABE, K.; GOTO, A.; NISHIMURA, J.; SHIBATA, H.; NAGAO, M.; SASAKI, S.; HASHIMOTO, S.; OKAMOTO, T.; SAKAIDA, I. Preliminary study of photodynamic diagnosis using 5 -aminolevulinic acid in gastric and colorectal tumors. World Journal of Gastroenterology : WJG, v. 21, n. 21, p. 6706-6712, 2015. ISSN 1007-93272219-2840. 
NAKAMURA, T.; OINUMA, T. Usefulness of Photodynamic Diagnosis and Therapy using Talaporfin Sodium for an Advanced-aged Patient with Inoperable Gastric Cancer (a secondary publication). Laser Therapy, v. 23, n. 3, p. 201-210, 2014. ISSN 0898-59011884-7269.

NAKAMURA, T.; OINUMA, T.; YAMAGISHI, H.; MASUYAMA, H.; TERANO, A. Evaluation of a novel high-resolution magnifying videoendoscope that is capable of photodynamic diagnosis and therapy for gastric cancer. Photodiagnosis and Photodynamic Therapy, v. 12, n. 1, p. 115-122, 2015.

NAMIKAWA, T.; YATABE, T.; INOUE, K.; SHUIN, T.; HANAZAKI, K. Clinical applications of 5-aminolevulinic acid-mediated fluorescence for gastric cancer. World Journal of Gastroenterology : WJG, v. 21, n. 29, p. 8769-8775, 2015. ISSN 100793272219-2840.

NGUYEN, J. T.; ASHITATE, Y.; BUCHANAN, I. A.; IBRAHIM, A. M.; GIOUX, S.; PATEL, P. P.; FRANGIONI, J. V.; LEE, B. T. Face transplant perfusion assessment using near-infrared fluorescence imaging. J Surg Res, v. 177, n. 2, p. e83-8, Oct 2012. ISSN 0022-4804.

NOGUEIRA, A. C.; GRACIANO, A. X.; NAGATA, J. Y.; FUJIMAKI, M.; TERADA, R. S.; BENTO, A. C.; ASTRATH, N. G.; BAESSO, M. L. Photosensitizer and light diffusion through dentin in photodynamic therapy. J Biomed Opt, v. 18, n. 5, p. 55004, May 2013. ISSN 1083-3668.

NYMAN, E. S.; HYNNINEN, P. H. Research advances in the use of tetrapyrrolic photosensitizers for photodynamic therapy. J Photochem Photobiol B, v. 73, n. 1-2, p. 1-28, Jan 23 2004. ISSN 1011-1344.

O'CONNOR, A. E.; GALLAGHER, W. M.; BYRNE, A. T. Porphyrin and nonporphyrin photosensitizers in oncology: preclinical and clinical advances in photodynamic therapy. Photochem Photobiol, v. 85, n. 5, p. 1053-74, Sep-Oct 2009. ISSN 00318655.

OSADA, T.; ARAKAWA, A.; SAKAMOTO, N.; UEYAMA, H.; SHIBUYA, T.; OGIHARA, T.; YAO, T.; WATANABE, S. Autofluorescence imaging endoscopy for identification and assessment of inflammatory ulcerative colitis. World $\mathbf{J}$ Gastroenterol, v. 17, n. 46, p. 5110-6, Dec 14 2011. ISSN 1007-9327.

POH, C. F.; ZHANG, L.; ANDERSON, D. W.; DURHAM, J. S.; WILLIAMS, P. M.; PRIDDY, R. W.; BEREAN, K. W.; NG, S.; TSENG, O. L.; MACAULAY, C.; ROSIN, M. $P$. Fluorescence visualization detection of field alterations in tumor margins of oral cancer patients. Clin Cancer Res, v. 12, n. 22, p. 6716-22, Nov 15 2006. ISSN 1078-0432.

POLSACHEV, V. I.; ALEKSEITSEVA, S. P.; ESAIAN, G. M.; LAZAREV, V. V. Use of the fluorescent analysis in early diagnosis of cancer of the stomach. Klin Khir, n. 5, p. 10-3, 1992. 
PUSHPAN, S. K.; VENKATRAMAN, S.; ANAND, V. G.; SANKAR, J.; PARMESWARAN, D.; GANESAN, S.; CHANDRASHEKAR, T. K. Porphyrins in photodynamic therapy - a search for ideal photosensitizers. Curr Med Chem Anticancer Agents, v. 2, n. 2, p. 187-207, Mar 2002. ISSN 1568-0118.

RAMANUJAM, N. Fluorescence spectroscopy of neoplastic and non-neoplastic tissues. Neoplasia, v. 2, n. 1-2, p. 89-117, Jan-Apr 2000. ISSN 1522-8002.

RICHARDS-KORTUM, R.; SEVICK-MURACA, E. Quantitative optical spectroscopy for tissue diagnosis. Annu Rev Phys Chem, v. 47, p. 555-606, 1996. ISSN 0066426X.

ROBERTS-THOMSON, I. C.; SINGH, R.; TEO, E.; NGUYEN, N. Q.; LIDUMS, I. The future of endoscopy. J Gastroenterol Hepatol, v. 25, n. 6, p. 1051-7, Jun 2010. ISSN 0815-9319.

ROESSLER, K.; BECHERER, A.; DONAT, M.; CEJNA, M.; ZACHENHOFER, I. Intraoperative tissue fluorescence using 5-aminolevolinic acid (5-ALA) is more sensitive than contrast MRI or amino acid positron emission tomography ((18)F-FET PET) in glioblastoma surgery. Neurol Res, v. 34, n. 3, p. 314-7, Apr 2012. ISSN 0161-6412.

ROSENTHAL, I. Phthalocyanines as photodynamic sensitizers. Photochem Photobiol, v. 53, n. 6, p. 859-70, Jun 1991. ISSN 0031-8655.

SAETTI, R.; DEROSAS, F.; SILVESTRINI, M.; NARNE, S. Efficacy of autofluoroscence videoendoscopy in the diagnosis of laryngeal lesions. Acta Otorhinolaryngol Ital, v. 27, n. 4, p. 181-5, Aug 2007. ISSN 0392-100X.

SANTIN, G. C.; OLIVEIRA, D. S.; GALO, R.; BORSATTO, M. C.; CORONA, S. A. Antimicrobial photodynamic therapy and dental plaque: a systematic review of the literature. Scientific World Journal, v. 2014, p. 824538, 2014. ISSN 1537-744x.

SCHULMAN, S. G.; SANDERS, L. B. Fluorescence and phosphorescence of 5- and 8-aminoquinoline. Analytica Chimica Acta, v. 56, n. 1, p. 83-89, 1971. ISSN 00032670.

SENGE, M. O. mTHPC--a drug on its way from second to third generation photosensitizer? Photodiagnosis Photodyn Ther, v. 9, n. 2, p. 170-9, Jun 2012. ISSN 1572-1000.

SESSLER, J. L.; WEGHORN, S. J. Expanded, Contracted \& Isomeric Porphyrins. Elsevier Science, 1997. ISBN 9780080535234.

SHAKIBAIE, F.; GEORGE, R.; WALSH, L. J. Applications of laser induced fluorescence in dentistry. International Journal of Dental Clinics, v. 3, n. 3, 2011. ISSN 0975-8437. 
SIERON, A.; KWIATEK, S. Twenty years of experience with PDD and PDT in Poland--review. Photodiagnosis Photodyn Ther, v. 6, n. 2, p. 73-8, Jun 2009. ISSN 1572-1000.

SIERON, A.; SIERON-STOLTNY, K.; KAWCZYK-KRUPKA, A.; LATOS, W.; KWIATEK, S.; STRASZAK, D.; BUGAJ, A. M. The role of fluorescence diagnosis in clinical practice. Onco Targets Ther, v. 6, p. 977-82, 2013. ISSN 1178-6930.

SIERON-STOLTNY, K.; KWIATEK, S.; LATOS, W.; KAWCZYK-KRUPKA, A.; CIESLAR, G.; STANEK, A.; ZIAJA, D.; BUGAJ, A. M.; SIERON, A. Autofluorescence endoscopy with "real-time" digital image processing in differential diagnostics of selected benign and malignant lesions in the oesophagus. Photodiagnosis Photodyn Ther, v. 9, n. 1, p. 5-10, Mar 2012. ISSN 1572-1000.

SMITH, R. A. The Colours of Life: An Introduction to the Chemistry of Porphyrins and Related Compounds (Milgrom, Lionel R.). Journal of Chemical Education, v. 75, n. 4, p. 420, 1998. ISSN 0021-9584.

SOUMYA, M. S.; SHAFEEKH, K. M.; DAS, S.; ABRAHAM, A. Symmetrical diiodinated squaraine as an efficient photosensitizer for PDT applications: Evidence from photodynamic and toxicological aspects. Chemico-Biological Interactions, v. 222, p. 44-49, 10/5/ 2014. ISSN 0009-2797.

SPIKES, J. D. Phthalocyanines as photosensitizers in biological systems and for the photodynamic therapy of tumors. Photochem Photobiol, v. 43, n. 6, p. 691-9, Jun 1986. ISSN 0031-8655.

STEIN, H. J.; SIEWERT, J. R. Barrett's esophagus: pathogenesis, epidemiology, functional abnormalities, malignant degeneration, and surgical management. Dysphagia, v. 8, n. 3, p. 276-88, 1993. ISSN 0179-051X.

STOOKEY, G. K. Optical methods--quantitative light fluorescence. J Dent Res, v. 83 Spec No C, p. C84-8, 2004. ISSN 0022-0345 (Print)

$0022-0345$.

STOOKEY, G.K. Quantitative light fluorescence: a technology for early monitoring of the caries process. Dent Clin North Am, v. 49, n. 4, p. 753-70, vi, Oct 2005. ISSN 0011-8532.

STRACHAN, J.-P.; O'SHEA, D. F.; BALASUBRAMANIAN, T.; LINDSEY, J. S. Rational Synthesis of Meso-Substituted Chlorin Building Blocks. The Journal of Organic Chemistry, v. 65, n. 10, p. 3160-3172, 2000. ISSN 0022-3263.

STURM, M. B.; WANG, T. D. Emerging optical methods for surveillance of Barrett's oesophagus. Gut, May 14 2015. ISSN 0017-5749.

TANABE, S.; YAMAGUCHI, M.; IIJIMA, M.; NAKAJIMA, S.; SAKATA, I.; MIYAKI, S., TAKEMURA, T.; FURUOKA, H.; KOBAYASHI, Y.; MATSUI, T.; UZUKA, Y.; SARASHINA, T. Fluorescence detection of a new photosensitizer, PAD-S31, in 
tumour tissues and its use as a photodynamic treatment for skin tumours in dogs and a cat: a preliminary report. Vet J, v. 167, n. 3, p. 286-93, May 2004. ISSN 1090-0233.

TURNER, G. G.; METEYER, C. U.; BARTON, H.; GUMBS, J. F.; REEDER, D. M.; OVERTON, B.; BANDOUCHOVA, H.; BARTONICKA, T.; MARTINKOVA, N.; PIKULA, J.; ZUKAL, J.; BLEHERT, D. S. Nonlethal screening of bat-wing skin with the use of ultraviolet fluorescence to detect lesions indicative of white-nose syndrome. J WildI Dis, v. 50, n. 3, p. 566-73, Jul 2014. ISSN 0090-3558.

VALEUR, B. Fluorescent Molecular Sensors of lons and Molecules. In: (Ed.). Molecular Fluorescence: Wiley-VCH Verlag GmbH, 2001. p.273-350. ISBN 9783527600243.

VASILCHENKO, S. Y.; VOLKOVA, A. I.; RYABOVA, A. V.; LOSCHENOV, V. B.; KONOV, V. I.; MAMEDOV, A. A.; KUZMIN, S. G.; LUKYANETS, E. A. Application of aluminum phthalocyanine nanoparticles for fluorescent diagnostics in dentistry and skin autotransplantology. J Biophotonics, v. 3, n. 5-6, p. 336-46, Jun 2010. ISSN 1864-063x.

WIDHALM, G.; WOLFSBERGER, S.; MINCHEV, G.; WOEHRER, A.; KRSSAK, M.; CZECH, T.; PRAYER, D.; ASENBAUM, S.; HAINFELLNER, J. A.; KNOSP, E. 5Aminolevulinic acid is a promising marker for detection of anaplastic foci in diffusely infiltrating gliomas with nonsignificant contrast enhancement. Cancer, v. 116, n. 6, p. 1545-52, Mar 2010. ISSN 0008-543X.

WOLUN-CHOLEWA, M.; SZYMANOWSKI, K.; NOWAK-MARKWITZ, E.; WARCHOL, W. Photodiagnosis and photodynamic therapy of endometriotic epithelial cells using 5-aminolevulinic acid and steroids. Photodiagnosis Photodyn Ther, v. 8, n. 1, p. 58-63, Mar 2011. ISSN 1572-1000.

XU, P.; CHEN, J.; CHEN, Z.; ZHOU, S.; HU, P.; CHEN, X.; HUANG, M. ReceptorTargeting Phthalocyanine Photosensitizer for Improving Antitumor Photocytotoxicity. PLoS ONE, San Francisco, USA, v. 7, n. 5, p. e37051, 2012. ISSN 1932-6203.

YAMADA, S.; MURAGAKI, Y.; MARUYAMA, T.; KOMORI, T.; OKADA, Y. Role of neurochemical navigation with 5-aminolevulinic acid during intraoperative MRIguided resection of intracranial malignant gliomas. Clin Neurol Neurosurg, v. 130, p. 134-9, Mar 2015. ISSN 0303-8467.

YAMAMOTO, T.; ISHIKAWA, E.; MIKI, S.; SAKAMOTO, N.; ZABORONOK, A.; MATSUDA, M.; AKUTSU, H.; NAKAI, K.; TSURUTA, W.; MATSUMURA, A. Photodynamic Diagnosis Using 5-Aminolevulinic Acid in 41 Biopsies for Primary Central Nervous System Lymphoma. Photochemistry and Photobiology, p. 121, 2015. ISSN 1751-1097.

ZHAO, H. L.; CHEN, Y.; ZHAO, H. J.; TAN, Z. J.; ZHANG, C. P.; FU, X. B.; MA, K. Autofluorescence of eccrine sweat glands. Skin Research and Technology, p. 59, 2015. ISSN 1600-0846. 
ZLATEV, D. V.; ALTOBELLI, E.; LIAO, J. C. Advances in Imaging Technologies in the Evaluation of High-Grade Bladder Cancer. Urologic Clinics of North America, v. 42, n. 2, p. 147-157, 2015. ISSN 0094-0143. 